\title{
Study of risk factors and perinatal outcome in meconium stained deliveries from a district of Uttar Pradesh, India
}

\author{
Richa Rathoria ${ }^{1}$, Ekansh Rathoria ${ }^{2 *}$, Utkarsh Bansal $^{2}$, Madhulika Mishra ${ }^{1}$, \\ Ila Jalote', Nirpal Kaur Shukla ${ }^{3}$, Dhruva Agarwal ${ }^{3}$
}

\begin{abstract}
${ }^{1}$ Department of Obstetrics and Gynecology, ${ }^{2}$ Department of Pediatrics, ${ }^{3}$ Department of Community Medicine, Hind Institute of Medical Sciences, Safedabad, Barabanki, Uttar Pradesh, India
\end{abstract}

Received: 14 August 2018

Accepted: 18 August 2018

\section{*Correspondence:}

Dr. Ekansh Rathoria,

E-mail: rathoriaekansh@yahoo.com

Copyright: $(\mathcal{C}$ the author(s), publisher and licensee Medip Academy. This is an open-access article distributed under the terms of the Creative Commons Attribution Non-Commercial License, which permits unrestricted non-commercial use, distribution, and reproduction in any medium, provided the original work is properly cited.

\begin{abstract}
Background: The objective is to identify the risk factors of Meconium stained deliveries and evaluate the perinatal outcomes in Meconium Stained deliveries.

Methods: This prospective observational study included those pregnant women who had completed 37 weeks of gestation, with singleton pregnancies with cephalic presentations and with no known fetal congenital anomalies. Among these, we selected 110 cases with Meconium stained amniotic fluid and they were compared with 110 randomly selected controls.

Results: Regular antenatal visits were seen in $22.73 \%$ of the cases while $77.27 \%$ cases had no previous visit. Majority of cases were primigravida and gestational ages of $>40$ weeks was seen in $55.45 \%$ cases. $19.09 \%$ cases had meconium staining among pregnancies complicated with pregnancy induced hypertension, as compared to those among controls $(5.45 \%)$. Fetal heart rate abnormalities were seen in $29.09 \%$ cases, and statistically significant fetal bradycardia was seen in cases. Caesarean section rates were nearly double in cases $(54.55 \%)$. Poor perinatal outcome was found in cases as seen in results by low Apgar score $(<7)$ at 1 minute and 5 -minute, higher incidence of birth asphyxia, Meconium Aspiration Syndrome and increased NICU admission as compared to that among controls.

Conclusions: Meconium stained amniotic fluid is more commonly associated with higher gestational age $>40$ weeks, pregnancy induced hypertension and fetal bradycardia, increased cesarean section rates, low APGAR score and higher incidence of birth asphyxia and NICU admissions. Meconium aspiration syndrome was associated with early neonatal death.
\end{abstract}

Keywords: Birth asphyxia, Meconium aspiration syndrome, Meconium stained amniotic fluid

\section{INTRODUCTION}

In utero, passage of meconium is relatively common occurring to $7-22 \%$ of all term deliveries. ${ }^{1}$ Meconium passage is rare before 34 weeks of gestation and incidence increases steadily beyond 37 weeks of gestation. $^{2}$ The exact etiology of in utero passage of meconium remains unclear. ${ }^{3,4}$ Various risk factors like advanced gestational age at delivery, increased duration of rupture of membranes (ROM), prolonged second stage of labor, and intra-amniotic infection, placental insufficiency, maternal hypertension, pre-eclampsia, oligohydroamnios or maternal drug abuse (tobacco or cocaine) are associated with meconium staining of amniotic fluid. ${ }^{5-11}$ Abnormal fetal heart rate in MSAF deliveries leads to increased perinatal morbidity thus requiring the need for continuous fetal heart rate monitoring/fetal blood sampling. ${ }^{12,13}$ 
Presence of meconium below the vocal cords is known as Meconium aspiration and it is seen in 20-30\% of all infants with meconium-stained amniotic fluid (MSAF). ${ }^{14}$ As compared to neonates born through clear amniotic fluid, neonates with MSAF are 100 times more likely to develop respiratory distress. ${ }^{15}$ Respiratory distress in a neonate born through MSAF with radiographic changes of aspiration pneumonitis may be defined as Meconium aspiration syndrome. ${ }^{16}$ About $5 \%$ of the babies born through meconium stained amniotic fluid develop meconium aspiration syndrome and the mortality rate of these babies vary from $4-7 \% .^{17}$

In deliveries complicated with MSAF, there is an increased risk of caesarean section, chorioamnionitis and puerperal sepsis along with higher morbidity and mortality in mother while the unfavorable outcomes in neonate include increased risks of birth asphyxia and fetal distress, low Apgar scores, increased incidence of neonatal intensive care unit (NICU) admission, meconium aspiration syndrome and early neonatal death. ${ }^{18,19}$

Meconium stained amniotic fluid is really alarming for both obstetrician and pediatrician and thus taking the risks into consideration, this study was done to identify the associated risk factors of meconium stained deliveries and compare the perinatal outcome in deliveries complicated by meconium staining versus clear liquor.

\section{METHODS}

This prospective observational study was carried out in the Department of Obstetrics and Gynaecology and Department of Pediatrics, Hind Institute of Medical Science, Safedabad, Barabanki, Uttar Pradesh, India, over a period of 12 months, from March 2017 to February 2018.

\section{Inclusion criteria}

Included all pregnant women who had completed more than 37 weeks of gestation, with singleton pregnancies with cephalic presentations and with no known fetal congenital anomalies.

\section{Exclusion criteria}

Included pregnancies which had completed less than 37 weeks of gestation; with presentations other than cephalic presentations and with known fetal congenital abnormalities.

After spontaneous or artificial rupture of membranes, patients with meconium stained amniotic fluid (MSAF) were taken as cases while patients with clear liquor were taken as control group. 110 cases with MSAF were thus selected and they were compared with 110 randomly selected controls. A detailed antenatal history along with clinical examination and investigations were done. The patients were watched for progress of labour and foetal heart rate monitoring was done by doing intermittent auscultations. Patients with maternal co-morbidities (severe anemia, PIH, pre-labour rupture of membranes etc.) were closely monitored. Fetal heart rate monitoring by cardiotocography was done for 20 minutes in MSAF cases and taking into consideration regarding all obstetric conditions, mode of delivery was then decided. Evaluation of perinatal outcome was based on apparently healthy baby, APGAR score (<7) at $1 \mathrm{~min}$ and $5 \mathrm{~min}$, meconium aspiration syndrome (MAS), birth asphyxia, neonatal sepsis, respiratory distress, seizures, HIE, neonatal intensive care unit (NICU) admissions, duration of NICU stay and early neonatal death (death within seven days of birth), etc. All the information was noted in systematic way in a pre-designed Performa regarding cases and controls.

Chi-square test was used for statistical analysis of results.

\section{RESULTS}

In present study, $77.27 \%$ were unbooked deliveries and only $22.73 \%$ were booked deliveries (at least 3 visits, with first visit in first trimester) among 110 cases with meconium stained amniotic fluid (MSAF). Among the cases, $60 \%$ women were of 20-30 years age-group and $51.82 \%$ pregnant females were primigravida, while $48.18 \%$ were multigravida (Table 1 ).

Table1: Prevalence of MSAF in relation to booking status, maternal age and parity.

\begin{tabular}{|llll|}
\hline Maternal parameters & Cases $(\%)$ & Control $(\%)$ \\
\hline Booked & & $25(22.73)$ & $44(40)$ \\
\hline Unbooked & & $85(77.27)$ & $66(60)$ \\
\hline \multirow{2}{*}{$\begin{array}{l}\text { Maternal } \\
\text { age }\end{array}$} & $<20$ years & $15(13.64)$ & $10(9.09)$ \\
\cline { 2 - 4 } & 20-30 years & $66(60)$ & $73(66.36)$ \\
\hline Parity & $>30$ years & $29(26.36)$ & $27(24.55)$ \\
\hline & Primi & $57(51.82)$ & $46(41.82)$ \\
\hline & G2-G4 & $35(31.82)$ & $53(48.18)$ \\
\hline & G5 and above & $18(16.36)$ & $11(10)$ \\
\hline
\end{tabular}

In present study, $55.45 \%$ cases had gestational age more than 40 weeks as compared to $14.55 \%$ controls that showed similar gestational ages which signify that increasing gestational age increases meconium staining of amniotic fluid (Table-2). Among the cases, severe anemia (hemoglobin $<7$ gram\%) was seen in around $12.73 \%$ cases, pregnancy induced hypertension (PIH) was seen in $19.09 \%$ cases, pre-labour rupture of membranes was seen in $11.82 \%$ cases, fetal bradycardia in $22.73 \%$ cases and fetal tachycardia in $6.36 \%$ cases.

As compared to those among controls (5.45\%), pregnancies complicated with PIH had higher rates of meconium staining (19.09\%) among the cases and was found to be statistically significant $(\mathrm{p}$-value $<0.05)$. Fetal heart rate abnormalities was seen in $29.09 \%$ cases and statistically significant fetal bradycardia was seen among 
cases as compared to that in controls ( $p$-value $<0.05$ ) (Table-3).

Table 2: Prevalence of MSAF in relation to gestational age.

\begin{tabular}{|llll|}
\hline \multirow{4}{*}{ Parameters } & & Cases $(\%)$ & Control $(\%)$ \\
& $37-38$ weeks & $11(10)$ & $20(18.18)$ \\
\cline { 2 - 4 } Gestational & $>38-39$ weeks & $16(14.55)$ & $39(35.45)$ \\
\cline { 2 - 4 } age & $>39-40$ weeks & $22(20)$ & $35(31.82)$ \\
\cline { 2 - 4 } & $>40-41$ weeks & $24(21.82)$ & $9(8.19)$ \\
& $>41-42$ weeks & $30(27.27)$ & $6(5.45)$ \\
\cline { 2 - 4 } & $>42$ weeks & $7(6.36)$ & $1(0.91)$ \\
\hline
\end{tabular}

Table 3: Relation of ante partum and intrapartum risk factors with meconium stained amniotic fluid.

\begin{tabular}{|llll|}
\hline Parameters & $\begin{array}{l}\text { Cases* } \\
(\%)\end{array}$ & $\begin{array}{l}\text { Control** } \\
(\%)\end{array}$ & p-value \\
\hline $\begin{array}{l}\text { Anemia } \\
\text { (hemoglobin }<7\end{array}$ & $14(12.73)$ & $6(5.45)$ & 0.07 \\
gram \%) & $21(19.09)$ & $6(5.45)$ & 0.0038 \\
\hline $\begin{array}{l}\text { Pregnancy induced } \\
\text { hypertension }\end{array}$ & $13(11.82)$ & $11(10)$ & 0.68 \\
\hline $\begin{array}{l}\text { Prelabour rupture } \\
\text { of membrane }\end{array}$ & $25(22.73)$ & $4(3.64)$ & 0.000096 \\
\hline $\begin{array}{l}\text { Fetal bradycardia } \\
\text { Fetal tachycardia }\end{array}$ & $7(6.36)$ & $4(3.64)$ & 0.36 \\
\hline * statistically significant $(\mathrm{p}<0.05)$ & & \\
\hline
\end{tabular}

Spontaneous vaginal delivery rate was $37.27 \%$ and $70.91 \%$ among cases and control group respectively. The rate of caesarean section in control and MSAF cases were found to be $25.45 \%$ and $54.55 \%$ respectively and found to be statistically significant when compared between these two groups ( $\mathrm{p}$-value $<0.05)$. Instrumental deliveries were done in $8.18 \%$ of cases with MSAF as compared to $3.64 \%$ among controls (Table 4).

Table 4: Mode of delivery among cases and control group.

\begin{tabular}{|c|c|c|c|}
\hline $\begin{array}{l}\text { Mode of } \\
\text { delivery }\end{array}$ & $\begin{array}{l}\text { Cases* } \\
(\%)\end{array}$ & $\begin{array}{l}\text { Control* } \\
(\%)\end{array}$ & p-value \\
\hline $\begin{array}{l}\text { Spontaneous } \\
\text { vaginal delivery }\end{array}$ & $41(37.27)$ & $78(70.91)$ & 0.00069 \\
\hline $\begin{array}{l}\text { Instrumental } \\
\text { delivery }\end{array}$ & $9(8.18)$ & $4(3.64)$ & 0.16 \\
\hline $\begin{array}{l}\text { Caesarean } \\
\text { section }\end{array}$ & $60(54.55)$ & $28(25.45)$ & 0.00064 \\
\hline
\end{tabular}

$74.55 \%$ babies were asymptomatic at birth among the cases as compared to $91.82 \%$ babies among controls. Babies with MSAF had low Apgar scores at birth and $25.45 \%$ cases needed neonatal intensive care unit admissions (p-value $<0.05)$. Meconium aspiration syndrome was seen in 4 cases $(3.64 \%)$ and all the 4 babies who were born to these cases had early neonatal deaths, though the difference was not statistically significant as compared to controls. Babies born to MSAF cases had statistically higher incidence of birth asphyxia and NICU admissions as compared to those who were born to control group (p-value<0.05) (Table 5).

Table 5: Perinatal outcome among MSAF cases and control group.

\begin{tabular}{|c|c|c|c|}
\hline Parameter & $\begin{array}{l}\text { Cases* } \\
(\%)\end{array}$ & $\begin{array}{l}\text { Control* } \\
(\%)\end{array}$ & $\begin{array}{l}\mathrm{p}- \\
\text { value }\end{array}$ \\
\hline $\begin{array}{l}\text { Asymptomatic } \\
\text { at birth }\end{array}$ & $82(74.55)$ & $101(91.82)$ & 0.16 \\
\hline $\begin{array}{l}\text { Apgar score at } 1 \\
\min (<7)\end{array}$ & $24(21.82)$ & $9(8.18)$ & 0.009 \\
\hline $\begin{array}{l}\text { Apgar score at } 5 \\
\min (<7)\end{array}$ & $13(11.82)$ & $8(7.27)$ & 0.27 \\
\hline $\begin{array}{l}\text { Meconium aspiration } \\
\text { syndrome }\end{array}$ & $4(3.64)$ & $1(0.91)$ & 0.17 \\
\hline Birth asphyxia & $19(17.27)$ & $7(6.36)$ & 0.018 \\
\hline Neonatal sepsis & $5(4.55)$ & $3(2.73)$ & 0.47 \\
\hline NICU admission & $28(25.45)$ & $11(10)$ & 0.0064 \\
\hline $\begin{array}{l}\text { Early neonatal } \\
\text { death }\end{array}$ & $4(3.64)$ & $1(0.91)$ & 0.17 \\
\hline
\end{tabular}

No significant difference was observed in terms of birth weight between cases and controls (Table-6).

Table 6: Birth weight of babies born to cases and control group.

\begin{tabular}{|lll|}
\hline Weight in gm & Cases (\%) & Control (\%) \\
\hline$=<2499 \mathrm{gm}$ & $15(13.64)$ & $19(17.28)$ \\
\hline 2500 to 2999 gm & $65(59.09)$ & $62(56.36)$ \\
\hline$>=3000 \mathrm{gm}$ & $30(27.27)$ & $29(26.36)$ \\
\hline
\end{tabular}

\section{DISCUSSION}

The passage of meconium in utero may be a normal physiological event representing the normal gastrointestinal maturation and indicating fetal maturity or it may reflect acute or chronic fetal hypoxia or increased vagal activity from cord compression. ${ }^{19}$ Meconium passage in utero and its associations is a frequent cause of perinatal morbidity and mortality.

In present study, $77.27 \%$ were unbooked deliveries among 110 cases with meconium stained amniotic fluid (MSAF) which was comparable with the study done by Bhide et al, which showed that a majority of cases with MSAF were unbooked. This study, in accordance with the study done by Sandu SS et al showed that the incidence of MSAF was higher in the age group of 20-30 years but this seemed to be a fortuitous finding. ${ }^{20,21}$ In this study, $55.45 \%$ cases had gestational age more than 40 weeks as compared to $14.55 \%$ controls that showed similar gestational ages which signify that increasing gestational age increases meconium staining of amniotic 
fluid. Present study was comparable to study done by Naveen $S$ et al which showed postdated pregnancy was one of the risk factors for MSAF. ${ }^{22}$

The incidence of pregnancy induced hypertension (PIH) associated with meconium stained amniotic fluid (MSAF) was $19.09 \%$ in this study which was higher than studies done by Hosna Ara Khatun et al where the incidence was $13.8 \%$ and Mundhra $\mathrm{R}$ et al where the incidence was $16.97 \%$. In utero passage of meconium in $\mathrm{PIH}$ patients is because of fetal hypoxia due to uteroplacental insufficiency. ${ }^{23,24}$

The rate of caesarean section in MSAF cases were found to be $54.55 \%$ in present study as compared to $45.7 \%$ in a study done by Unnisa $\mathrm{S}$ et al. ${ }^{25}$ Another study by Saunders et al found caesarean sections were done twice as frequently in MSAF cases. ${ }^{26}$ In contrast to present study, Wong SF found caesarean section rates to be $13.2 \%$ and $8.8 \%$ in patients with MSAF and clear amniotic fluid respectively indicating that lower rates of caesarean section might be because of scalp $\mathrm{pH}$ sampling in their study. ${ }^{27}$

Fetal outcome also depends on consistency of meconium. Infants with thin meconium are probably healthy at birth but still needs intensive fetal monitoring. Infants with thick meconium had five to seven times increased risk of perinatal death. In present study, cases were not divided based on consistency of meconium. ${ }^{28,29}$

In present study, $74.55 \%$ babies were asymptomatic at birth, 21.82\% had low Apgar scores at birth. As compared to present study, Patil et al found that $19 \%$ babies with MSAF had low Apgar scores.

Meconium aspiration syndrome was seen in $3.64 \%$ MSAF cases in this study which was comparable to study done by Patil et al which reported meconium aspiration syndrome in $12.8 \%$ of babies with MSAF. ${ }^{30}$ In present study, $25.45 \%$ MSAF cases needed neonatal intensive care unit admissions and $3.64 \%$ cases reported early neonatal death which was similar to studies done by Rajput $U$ et al which reported neonatal intensive care unit admissions in $24 \%$ cases and Gupta V et al which reported $4.9 \%$ cases with early neonatal death respectively. ${ }^{31,32}$

\section{CONCLUSION}

It is clearly seen in this study that Meconium stained amniotic fluid is more commonly associated with higher gestational age $>40$ weeks, pregnancy induced hypertension and fetal bradycardia, increased rate of cesarean delivery, increased need for neonatal resuscitation, low APGAR score and higher incidence of birth asphyxia with hypoxic ischemic encephalopathy and NICU admissions. Meconium aspiration syndrome was associated with early neonatal death.
Funding: No funding sources

Conflict of interest: None declared

Ethical approval: The study was approved by the Institutional Ethics Committee

\section{REFERENCES}

1. Siriwachirachai T, Sangkomkamhang US, Lumbiganon P, Laopaiboon M. Antibiotics for meconium-stained amniotic fluid in labour for preventing maternal and neonatal infections. The Cochrane database of systematic reviews. 2010(12):CD007772.

2. Steer PJ, Eigbe F, Lissauer TJ, Beard RW. Interrelationships among abnormal cardiotocograms in labor, meconium staining of the amniotic fluid, arterial cord blood $\mathrm{pH}$, and Apgar scores. Obstet Gynecol. 1989;74(5):715-21.

3. Ghidini A, Spong CY. Severe meconium aspiration syndrome is not caused by aspiration of meconium. Am J Obstet Gynecol 2001;185(4):931-8.

4. Katz VL, Bowes WA. Meconium aspiration syndrome: reflections on a murky subject. Am J Obstet Gynecol. 1992;166(1):171-83.

5. Shaikh EM, Mehmood S, Shaikh MA. Neonatal outcome in meconium stained amniotic fluid-one year experience. JPMA. 2010;60(711).

6. David AN, Njokanma OF, Iroha E. Incidence of and factors associated with meconium staining of the amniotic fluid in a Nigerian University Teaching Hospital. J Obstet Gynaecol. 2006;26(6):518-20.

7. Oyelese Y, Culin A, Ananth CV, Kaminsky LM, Vintzileos A, Smulian JC. Meconium-stained amniotic fluid across gestation and neonatal acidbase status. Obstet Gynecol. 2006;108(2):345-9.

8. Romero R, Hanaoka S, Mazor M, Athanassiadis AP, Callahan R, Hsu YC, et al. Meconium-stained amniotic fluid: a risk factor for microbial invasion of the amniotic cavity. Am J Obstet Gynecol. 1991;164(3):859-62.

9. Tran SH, Caughey AB, Musci TJ. Meconium-stained amniotic fluid is associated with puerperal infections. Am J Obstet Gynecol. 2003;189(3):746-50.

10. Cheng YW, Hopkins LM, Laros Jr RK, Caughey AB. Duration of the second stage of labor in multiparous women: maternal and neonatal outcomes. Am J Obstet Gynecol. 2007;196(6):585e1.

11. Burgess AM, Hutchins GM. Inflammation of the lungs, umbilical cord and placenta associated with meconium passage in utero: review of 123 autopsied cases. Pathol Res Pract. 1996;192(11):1121-8.

12. Eriksen NL, Hostetter M, Parisi VM. Prophylactic amnioinfusion in pregnancies complicated by thick meconium. Am J Obstet Gynecol. 1994;171(4):102630.

13. Miller FC, Sacks DA, Yeh SY, Paul RH, Schifrin BS, Martin CB, et al. Significance of meconium during labor. Am J Obstet Gynecol. 1975;122(5):573-80. 
14. Wiswell TE, Bent RC. Meconium staining and the meconium aspiration syndrome: unresolved issues. Pediat Clinic North Am. 1993;40(5):955-81.

15. Fleischer A, Anyaegbunam A, Guidetti D, Randolph G, Merkatz IR. A persistent clinical problem: profile of the term infant with significant respiratory complications. Obstet Gynecol. 1992;79(2):185-90.

16. Garg R, Masand R, Verma CR, Sharma GL, Yadav SA. Clinical profile of meconium aspiration syndrome in relation to birth weight and gestational age. Int J Contemp Pediat. 2018;5(3):726-31.

17. Ranee D, Phirke DS. Clinical profile of babies with meconium stained amniotic fluid. International J Res Med Sci. 2017;5(10):4319-23.

18. Maymon E, Chaim W, Furman B, Ghezzi F, Vardi IS, Mazor M. Meconium stained amniotic fluid in very low risk pregnancies at term gestation. Euro J Obstet Gynecol Reproduct Biol. 1998;80(2):169-73.

19. Ahanya SN, Lakshmanan J, Morgan BL, Ross MG. Meconium passage in utero: mechanisms, consequences, and management. Obstetrical and gynecological survey. 2005;60(1):45-56.

20. Bhide SS, Shendurnikar N, Aiyer S, Baxi SR. Neonatal outcome after meconium stained amniotic fluid. J Obstet Gynecol India. 1993;44:933-5.

21. Sandhu SK, Singh J, Khura H, Kaur H. Critical evaluation of meconium staining of amniotic fluid and foetal outcome. $\mathrm{J}$ Obstet Gynaecol India. 1993;43:528-3.

22. Naveen S, Kumar SV, Ritu S, Kushia P. Predictors of meconium stained amniotic fluid: a possible strategy to reduce neonatal morbidity and mortality. $\mathrm{J}$ Obstet Gynecol India. 2006;56(6):514-7.

23. Khatun MH, Arzu J, Haque E, Kamal MA, Al Mamun MA, Khan MF, Hoque MM. Fetal outcome in deliveries with meconium stained liquor. Ban J Child Health. 2009;33(2):41-5.

24. Mundhra R, Agarwal M. Fetal outcome in meconium stained deliveries. JCDR. 2013;7(12):2874.
25. Unnisa S, Sowmya BS, Rao SB, Rajagopal K. Maternal and fetal out come in meconium stained amniotic fluid in a tertiary centre. Int $\mathbf{J}$ Reprod Contracep Obstet Gynecol. 2017;5(3):813-7.

26. Saunders K. Should we worry about meconium? A controlled study of neonatal outcome. Trop Doc. 2002;32(1):7-10.

27. Wong SF, Chow KM, Ho LC. The relative risk of 'fetal distress' in pregnancy associated with meconium-stained liquor at different gestation. J Obstet Gynaecol. 2002;22(6):594-9.

28. Berkus MD, Langer O, Samueloff A, Xenakis EM, Field NT, Ridgway LE. Meconium-stained amniotic fluid: increased risk for adverse neonatal outcome. Obstet Gynecol. 1994;84(1):115-20.

29. Rossi EM, Philipson EH, Williams TG, Kalhan SC. Meconium aspiration syndrome: intrapartum and neonatal attributes. Am J Obstet Gynecol. 1989;161(5):1106-10.

30. Patil KP, Swamy MK, Samatha K. A one year cross sectional study of management practices of meconium stained amniotic fluid and perinatal outcome. Obstet Gynecol India. 2006;56:128-30.

31. Rajput U, Jain A. Impact of meconium stained amniotic fluid on early neonatal outcome. J Evol Med Dental Sci. 2013;2(45):8788-94.

32. Gupta V, Bhatia BD, Mishra OP. Meconium stained amniotic fluid: antenatal, intrapartum and neonatal attributes. Indian Pediat. 1996;33:293-8.

Cite this article as: Rathoria R, Rathoria E, Bansal U, Mishra M, Jalote I, Shukla NK et al Fetal Study of risk factors and perinatal outcome in meconium stained deliveries from a district of Uttar Pradesh, India. Int J Reprod Contracept Obstet Gynecol 2018;7:3605-9. 